\title{
Influence of Pre-strain on Very-Low-Cycle Stress-Strain Response and Springback Behavior
}

\author{
Khemais Barienti (D), Martin Klein, Steffen Wackenrohr, Sebastian Herbst, Florian Nürnberger, and Hans Jürgen Maier
}

Submitted: 22 July 2020 / Revised: 28 October 2020 / Accepted: 3 December 2020 / Published online: 4 January 2021

\begin{abstract}
The influence of pre-strain on the very-low-cycle loading behavior as occurring, for example during roller leveling of sheet metals, is not yet fully understood. A key factor in this context is the stiffness of the material and its changes upon processing. To study the general mechanical property changes during low-cycle loading with small amplitudes for a wide variety of metals, sheet samples of mild steel DC01, pure copper CU-DHP and $\alpha$-titanium are subjected to low-cycle tension-compression tests. The general influences of pre-strain and the applied strain amplitude are investigated regarding material hardening and changes in the elastic properties. It is shown that all tested materials feature changes in the Bauschinger behavior during cycling. The apparent elastic modulus of the materials decreases with increasing accumulated plastic strain, and the evolution depends on the strain amplitude and the pre-strain. For all three materials, changes in technical springback are present and depend on the loading history.
\end{abstract}

Keywords copper, elastic modulus, fatigue, plastic pre-deformation, springback, steel, titanium

\section{Introduction}

Springback has a decisive role in forming of components as it results in a distortion of the geometry of the finished product. A precise knowledge and prediction of springback are essential for industrial competitiveness, not only in terms of achievable quality but also in terms of productivity (Ref 1,2$)$. A key factor in this context is the stiffness of the material described by the apparent modulus of elasticity during loading and the so-called chord modulus during unloading (Ref 3). Both parameters are not constant but depend on the material used, the temperature, the sheet thickness and the pre-strain (Ref 2-5). Even very small pre-strains are sufficient to observe a reduction of both moduli (Ref 2). The reason for this phenomenon is not yet fully understood. Lattice defects such as accumulated dislocations or twins appear to play a key role in reducing both moduli. Other explanations are based on the prevalence of residual stresses (Ref 6) or time-dependent inelasticity (Ref 7). In order to counteract shape deviations in the final product and to enable near-net-shape production, the employed semi-finished sheets are often subjected to skin passing and a subsequent roller leveling. Both processes induce small amounts of deformation, which were shown to influence the springback behavior during subsequent forming operations (Ref 6). Skin passing induces small deformation especially in the sheet surfaces which can deteriorate the springback during subsequent bending (Ref 6). An additional roller leveling was shown to reduce the residual

Khemais Barienti, Martin Klein, Steffen Wackenrohr, Sebastian Herbst, Florian Nürnberger, and Hans Jürgen Maier, Institut für Werkstoffkunde (Materials Science), Leibniz Universität Hannover, An der Universität 2, 30823 Garbsen, Germany. Contact e-mail: barienti@iw.uni-hannover.de. stress state by alternating plastic bending, which was linked to a recovery of the deteriorated springback behavior caused by skin passing (Ref 6,8).

Previous investigations (Ref 9, 10) demonstrated a strong influence on the mechanical properties caused by a low-cycle alternating bending with small loading amplitudes, as is typical for roller leveling. After multiple cycles, the yield strength increased by up to $20 \%$ for the mild steel DC01 (Ref 9). The effect was also observed for other materials with hexagonal close-packed (titanium and magnesium) as well as facecentered cubic (copper) crystal structures. In addition to the changes in flow behavior, a change in material springback within the first cycles was evident.

A clear explanation for the dependence of the springback behavior on low-cycle loading with very small amplitudes is not yet established since a variety of parameters such as the microstructure, heat treatment, pre-strain, texture changes or residual stress changes play a role (Ref 2, 6, 8-10). Hence, the effect of alternating low-cycle uniaxial loading with very small deformation near the elastic-plastic transition was investigated in the present study. In addition, the influence of a pre-strain on the different materials and their elastic properties was determined.

\section{Methods}

In order to develop a basic understanding of the lattice structure on stress-strain response under very-low-cycle loading, materials with body-centered cubic (bcc), face-centered cubic (fcc) as well as hexagonal close-packed (hcp) crystal lattices were employed in the present study. Moreover, the materials should be of technical relevance and feature similar yield strength to avoid that the latter overshadows the effects of crystallography. To meet these requirements, a low carbon steel designed for cold forming (DC01, bcc), pure copper (Cu-DHP, fcc) and $\alpha$-titanium (grade 1, hcp) were selected. The respective chemical compositions determined by optical emission spectroscopy (OES) are summarized in Table 1. 
Table 1 Chemical compositions (wt.\%) as determined by OES

\begin{tabular}{llllllllll}
\hline & \multicolumn{1}{c}{$\mathbf{F e}$} & $\mathbf{T i}$ & $\mathbf{C u}$ & $\mathbf{C}$ & $\mathbf{M n}$ & $\mathbf{A l}$ & $\mathbf{C r}$ & $\mathbf{S i}$ & $\mathbf{S}$ \\
\hline $\mathrm{DC0} 1$ & Balance & $\ldots$ & $\ldots$ & 0.055 & 0.200 & 0.055 & 0.030 & 0.021 \\
$\alpha$-Ti & 0.033 & Balance & $\ldots$ & 0.033 & 0.011 & $\ldots$ & 0.014 \\
$\mathrm{Cu}-\mathrm{DHP}$ & $\ldots$ & $\ldots$ & 99.960 & $\ldots$ & $\ldots$ & $\ldots$ & $\ldots$ & 0.011 & $\ldots$ \\
\hline
\end{tabular}

Table 2 Heat pre-treatment parameters used

\begin{tabular}{lcccl}
\hline & Temperature, ${ }^{\circ} \mathbf{C}$ & Time, min & Atmosphere & Cooling \\
\hline $\mathrm{DC} 01$ & 580 & 15 & $\mathrm{Ar}$ & Furnace \\
$\alpha-\mathrm{Ti}$ & 580 & 30 & $\mathrm{Ar}$ & $\mathrm{Air}$ \\
$\mathrm{Cu}-\mathrm{DHP}$ & 175 & 30 & $\mathrm{Ar}$ & $\mathrm{Air}$ \\
\hline
\end{tabular}

In order to investigate the influence of pre-strain on the lowcycle mechanical behavior, strips measuring $200 \mathrm{~mm} \times 20 \mathrm{~mm}$ were prepared from $1 \mathrm{~mm}$ thick sheets. The strips were subjected to a material-specific heat pre-treatment in an electrical batch furnace. The heat treatment parameters employed are depicted in Table 2. The pre-treatments were carried out to ensure a similar initial condition and to reduce residual stresses. The monotonic stress-strain curves after heat pre-treatment are given in Fig. 1.

Following the heat treatment, the specimens were rolled at room temperature with a Bühler duo roll 135 at a rolling speed of $2 \mathrm{~mm} \mathrm{~s}^{-1}$. Fourteen samples of each material were subjected to a pre-strain of $5 \%$. Fourteen additional samples per material were employed in the subsequent analysis directly after heat treatment without any pre-strain. These two substantially different values of the pre-strain were selected to clearly bring out the effect of pre-strain and at the same time avoid excessive plastic deformation. The specimens for low-cycle tensilecompression testing were milled from the strips using the geometry shown in Fig. 2(c).

The cyclic tests were carried out on a Acumen $100 \mathrm{kN}$ (MTS) using a support structure as depicted in Fig. 2(b) to prevent buckling during compression. Before inserting the specimen, the contacting surfaces of both the support and the specimen were coated with graphite to reduce friction during testing. The narrow construction of the support further reduced friction and allowed for a measurement via an extensometer (12 $\mathrm{mm}$ gauge length) needed for strain-controlled testing as demonstrated in Fig. 2(a).

During the strain-controlled low-cycle testing, two different amplitudes $(0.23 \%$ and $0.52 \%)$ were applied for 15 loading cycles each. The selected amplitudes were intended to cover the elasto-plastic transition. During testing, the strain had a triangular wave shape with a strain rate magnitude of $0.25 \%$ $\mathrm{s}$ 1. Following the low-cycle test, the elastic springback behavior was evaluated. The specimens were bent to $\alpha_{\text {tar- }}$ get $=90^{\circ}$ with a bending radius of $6 \mathrm{~mm}$ in a Z250/SN5A-type materials testing machine (Zwick) with a crosshead speed of $1 \mathrm{~mm} \mathrm{~s}^{-1}$. To determine the springback, the angle $\alpha_{\exp }$ of the bent specimen was measured with an analog protractor. The difference between $\alpha_{\text {exp }}$ and $\alpha_{\text {target }}$ was calculated and then divided by $\alpha_{\text {target }}$. For statistical verification, every material condition was tested with seven samples each. An overview of the experiments performed is given in Fig. 3.

After each testing step, the residual stresses on the surface of the material DC01 were determined by XRD measurements using a Discover D8 diffractometer (Bruker) and employing the $\sin ^{2} \psi$ methodology with the Software Laptos S (Bruker). The residual stress was measured for one specimen that was followed along the different process steps. The measurements were conducted at three different points along the rolling direction. The measurements points were positioned in the middle of the sheets upper surface and spaced in equidistant intervals of $5 \mathrm{~cm}$. The residual stresses were determined for the initial state, after $5 \%$ pre-strain and after a subsequent cyclic loading with a strain amplitude of $0.52 \%$ for a DC01 sample. For titanium and copper, the data could not be evaluated reliably due to insufficient signal-to-noise ratios, and thus are not reported here.

\section{Results and Discussion}

\subsection{Strain Response under Short Cycle Loading}

3.1.1 Mild Steel: DC01. Typical stress-strain hysteresis curves for the material DC01 without pre-strain at cyclic strain amplitudes of $\frac{\Delta \varepsilon}{2}=0.23 \%$ and $\frac{\Delta \varepsilon}{2}=0.52 \%$ are shown in Fig. 4 . It is noted that despite the graphite used, some effect of support structure is seen in the stress-strain hysteresis in the initial loading cycle and upon stress reversal. These effects were accounted for in subsequent data analysis.

Both specimens feature a pronounced Lüders strain during the first tensile loading, which is followed by slight cyclic softening in the subsequent cycles. Quasi-static tests on the same material showed that the Lüders strain can reach values of up to $3 \%$. Due to the cyclic uniaxial loading, the elimination of the Lüders strain occurs at lower accumulated plastic strain, i.e., after just one load cycle. This behavior is consistent with reports in the literature in which it was shown that the effect of Lüders strain could be reduced by one alternating bending cycle in which only a small strain is introduced into the sheet surface (Ref 11).

The amplitudes used in the present study are up to an order of magnitude smaller than those used (Ref 11) and are based on previous works (Ref 9) on cyclic alternating bending. With the selected minimal amplitude of $0.23 \%$ strain, the point of elastic-plastic transition is exceeded only slightly. Nevertheless, this was sufficient to permanently eliminate the effect of Lüders strain under conditions of alternating cyclic stress states.

The development of both maximal tensile and compressive stresses of all investigated materials during cyclic testing is shown in Fig. 5. The error bars indicate the standard deviation of all tests performed. For the mild steel (Fig. 5a and b), a 

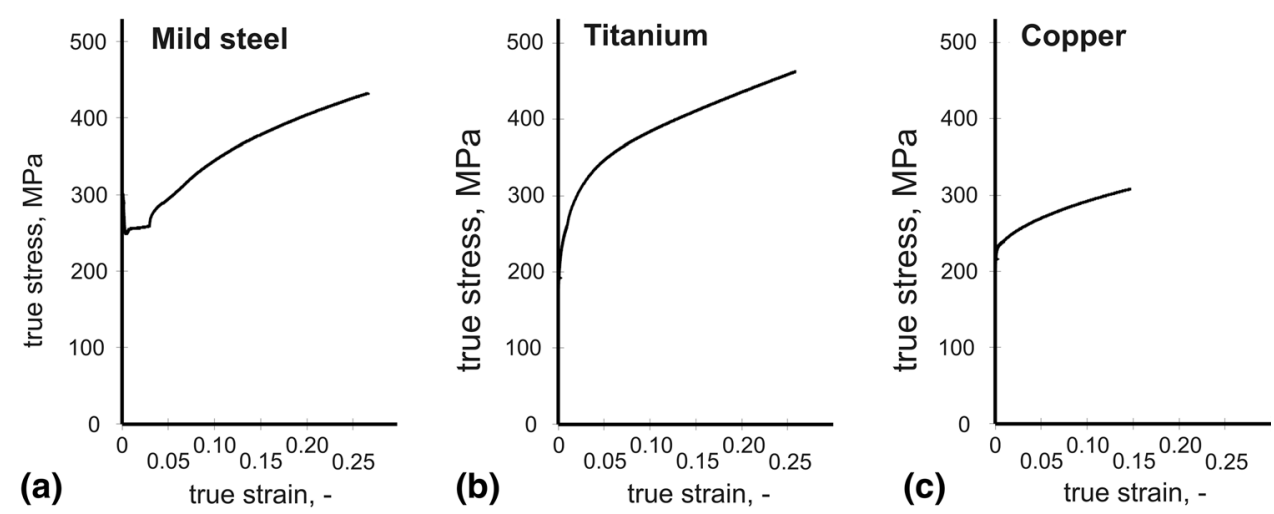

Figure 1 Monotonic stress-strain curves after heat pre-treatment for mild steel (a), titanium (b) and copper (c)

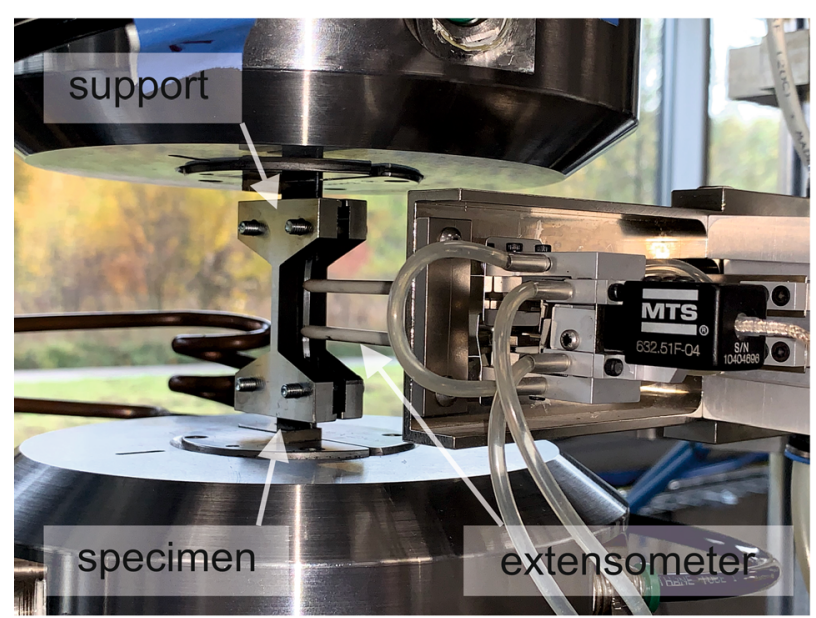

(a)

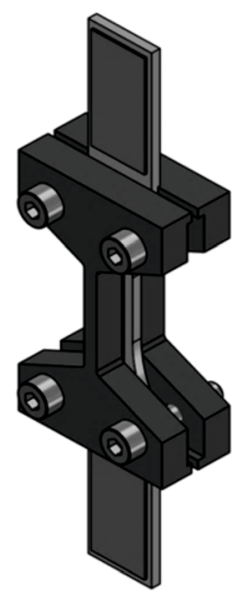

(b)

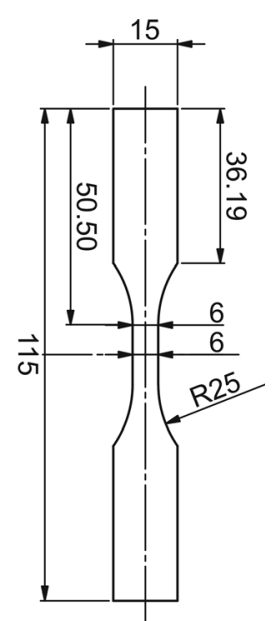

(c)

Figure 2 Experimental setup (a), illustration of the support structure (b) and specimen geometry in accordance with DIN 50125 (c)

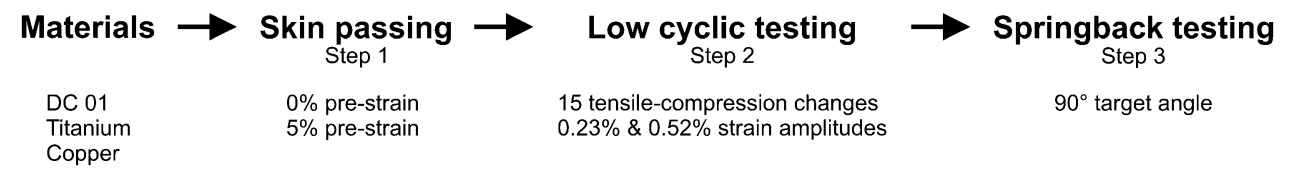

Figure 3 Overview of the testing sequence employed to determine springback

maximum softening of up to $18 \%$ compared to the first cycle after which the Lüders strain was eliminated can be observed during subsequent cyclic. Within the first two cycles, the softening is pronounced and then asymptotically saturates with increasing accumulated strain.

For all strain amplitudes the overall trends are similar and a noticeable impact of the previously induced pre-strain is apparent. As expected, no Lüders strain can be observed for a pre-strain of $5 \%$, which results in a lower maximum stress upon initial loading. As the specimens without pre-strain, the previously rolled specimens show a softening that asymptotically approaches a saturation. With $275 \mathrm{MPa}$, this is about $6 \%$ higher than for the material without pre-strain and can be linked to the work hardening introduced by the preceding skin passing. A similar softening behavior and a reduction of the chord modulus have also been observed in the literature (Ref 2, 4, 12).
Further there is a noticeable difference between tensile and compressive stresses, which is shown as the evolution of the Bauschinger parameter $\beta_{\mathrm{f}}$ as a function of the number of cycles (Fig. 6(a)). The parameter $\beta_{\mathrm{f}}$ represents the ratio of the yieldstress values between the tensile and subsequent compressive load in a cycle and is calculated as $\beta_{\mathrm{f}}=\frac{\sigma_{\mathrm{T}}-\sigma_{\mathrm{C}}}{2 \cdot \sigma_{\mathrm{T}}}$ from the yield stress under tension $\left(\sigma_{\mathrm{T}}\right)$ and under compression $\left(\sigma_{\mathrm{C}}\right)(\operatorname{Ref} 13)$.

Without pre-strain, the mild steel features a low sensitivity to load changes after the initial Lüders strain is eliminated. This is characterized by values of the parameter $\beta_{\mathrm{f}}$ close to 1 . The value stabilizes in the course of loading after about 5 cycles to a value of 0.96 . For the pre-strained material, a pronounced change from 0.85 to 0.92 is observed after the first cycle. However, upon further cyclic loading, the value remains almost constant and is permanently below the value of the samples without pre-strain. 


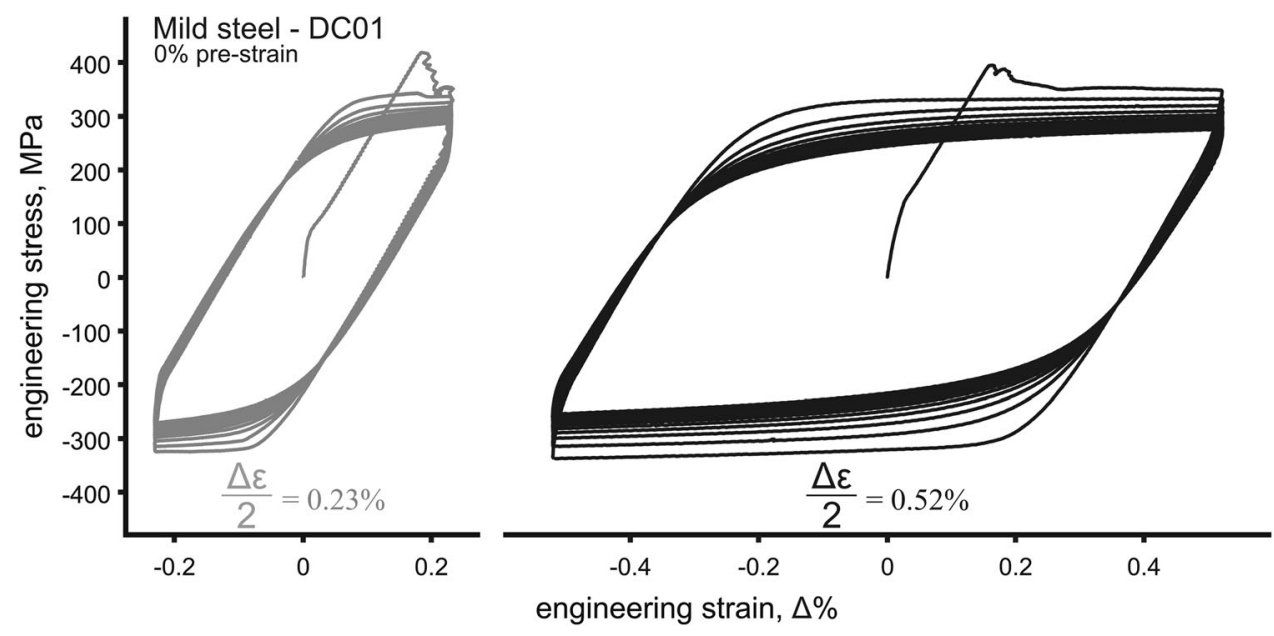

Figure 4 Stress-strain hysteresis curves measured for mild steel samples without pre-strain for both strain amplitudes employed

The surface residual stress along the rolling direction for different stages of testing is depicted in Fig. 6(b). The plotted data represent the mean values of all three measurements along the rolling direction including the calculated maximum error as determined using the software Leptos S. Although the error is rather large as is typical for residual stress measurements by $\mathrm{x}$ ray techniques in soft steels, the overall trends are clear from the data.

After the heat treatment, no residual stresses could be determined via XRD on the measured sheet surface. After the sheet was subjected to a $5 \%$ skin pass process, tensile residual stresses of $56 \pm 15 \mathrm{MPa}$ were determined. This behavior is consistent with observations in (Ref 14) and is due to frictioninduced inhomogeneous forming near the sheet surfaces. After 15 uniaxial alternating loading cycles, all previously introduced residual stresses were eliminated and only small residual stresses remain from plastic deformation upon cyclic loading itself (Fig. 6(b)). Micrographs of all materials examined in the heat-treated state and after passing the maximum loading $(5 \%$ pre-strain and $\frac{\Delta \varepsilon}{2}=0.52 \%$ ) are given in Fig. 7. For the mild steel no changes within the microstructure that can be revealed by optical microscopy are apparent, which is in accordance with previous research (Ref 9).

3.1.2 Titanium. In comparison with the material DC01, an asymmetric dependence of the strain hardening behavior on the pre-strain and the stress state is evident (Fig. 5(c) and (d)). Specifically, the magnitude of the stress upon compressive loading remains almost constant, whereas the magnitude of the stress upon tensile loading continuously decreases by up to $13 \%$ and approaches a saturation after about 10 cycles. The magnitude of the compressive stress is also up to $200 \mathrm{MPa}$ higher than the corresponding tensile stress, which is also reflected in a Bauschinger parameters $\beta \mathrm{f}>1$ (Fig. 6(a)). This effect occurs independently of pre-strain. Work hardening due to skin passing leads to a reduced loading sensitivity $\beta \mathrm{f}$.

Different than the mild steel, the hexagonal close-packed titanium demonstrated substantial microstructural changes, which is typical for hep materials under load. The titanium exhibited increased formation of twins, which could be observed on the entire cross section (Fig. 6). Titanium tends to form twins in alternating bending tests, where compressive stresses are present (Ref 10). This behavior can now be linked with the recorded stress differences for the two stress states.
Inducing mechanical twins under compression stabilizes the required stress for deformation and cyclic softening is only present during tension. This results in drastic asymmetric mechanical softening which is reflected by the wide range of values for $\beta \mathrm{f}$ recorded during the course of testing (Fig. 6(a)).

3.1.3 Copper. With an initial Bauschinger parameter $\beta_{\mathrm{f}}$ of about 0.85 (Fig. 6a), copper behaves similarly to DC01 with lower stresses under compression as a result of a previous tensile loading (Fig. 5(e) and (f)). The effect of a pre-strain on the low-cycle alternating load behavior is less pronounced compared to the other materials. In all tests on copper, a softening behavior was present, which was slightly enhanced by pre-straining the samples. For samples without pre-strain that were cycled at $\frac{\Delta \varepsilon}{2}=0.52 \%$, a softening of about $10 \%$ compared to the initial state occurred, which saturated for compression at about $225 \mathrm{MPa}$ and for tension at about 250 $\mathrm{MPa}$. Accordingly, the corresponding Bauschinger parameter asymptotically approached $\beta_{\mathrm{f}}=0.95$. The observed Bauschinger sensitivity showed no dependence on the applied pre-strain and a very low sensitivity to cyclic alternating loads at small strain amplitudes. Regarding the microstructure, no change in grain morphology could be detected (Fig. 7(c)). These observations coincide with previous investigations on the effect of low-cycle alternating bending loads (Ref 9). Of all the materials investigated, copper showed the lowest sensitivity of the measured properties to the applied pre-strain.

\subsection{Springback Behavior}

The springback after cyclic loading depends in particular on the material-specific elastic modulus. Changes of the overall material stiffness due to plastic deformation have already been demonstrated in the literature and are topic of ongoing research (Ref $2,3,12,15)$. As the true elastic modulus is a variable depending on atomic bond forces and distances, it changes with applied stress, and thus even the elastic part of the stress-strain curve shows nonlinear behavior. In the present study, the apparent elastic modulus, which describes general stiffness, was used to characterize the change of the elastic properties during cyclic loading. The apparent elastic modulus of each cycle was evaluated by linear regression of the slope of the true stress/true strain curves after each change in loading direction during cyclic testing (Ref 16). Changes of the apparent elastic modulus for the three investigated materials mild steel $(a, b)$, 

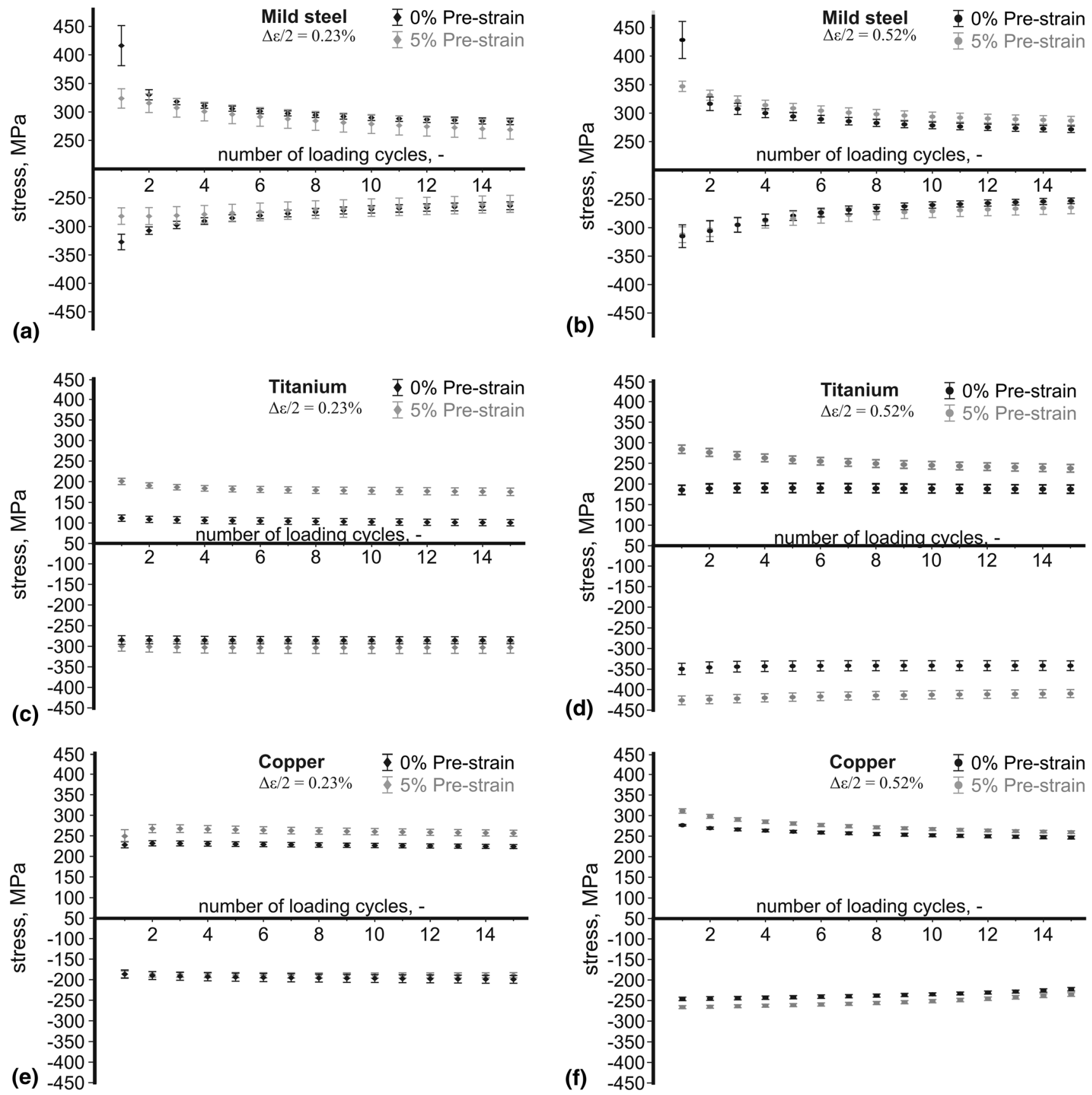

Figure 5 Maximum tensile and compressive stresses during cyclic testing as a function of pre-strain and strain amplitude for mild steel (a, b), titanium (c, d) and copper (e, f)

titanium (c, d) and copper (e, f) for the tensile and compression stress states are summarized in Fig. 8.

In line with observations in (Ref 2), the apparent elastic modulus of the mild steel decreases with increasing plastic strain by up to $25 \%$ depending on the test conditions. Moreover, the influence of pre-strain is quite pronounced. As expected, the samples with pre-strain already show slightly smaller modulus already for the first loading. The changes due to cyclic loading are especially pronounced during the first cycles, and a rapid saturation is seen in the further course of testing. A similar saturation was observed in previous investigations on cyclic bending regarding the physical springback behavior (Ref 9). Even in the saturated state, there is a noticeable difference in the apparent elastic modulus linked for the differing loading amplitudes. Thus, a loading path with a larger amplitude leads to lower values of the apparent elastic modulus at an equivalent accumulated plastic strain. This could support existing theories (Ref 2) regarding the importance of dislocation movement for the development of apparent elastic properties especially during alternating loading due to easier dislocation movement during load changes regarding the processes causing the Bauschinger effect (Ref 17). Looking at the values for titanium, a clear difference is also seen which depends on the type of stress state (Fig. 8(c) and (d)). As already shown for material hardening, titanium features a high sensitivity of the mechanical properties on the stress state due 

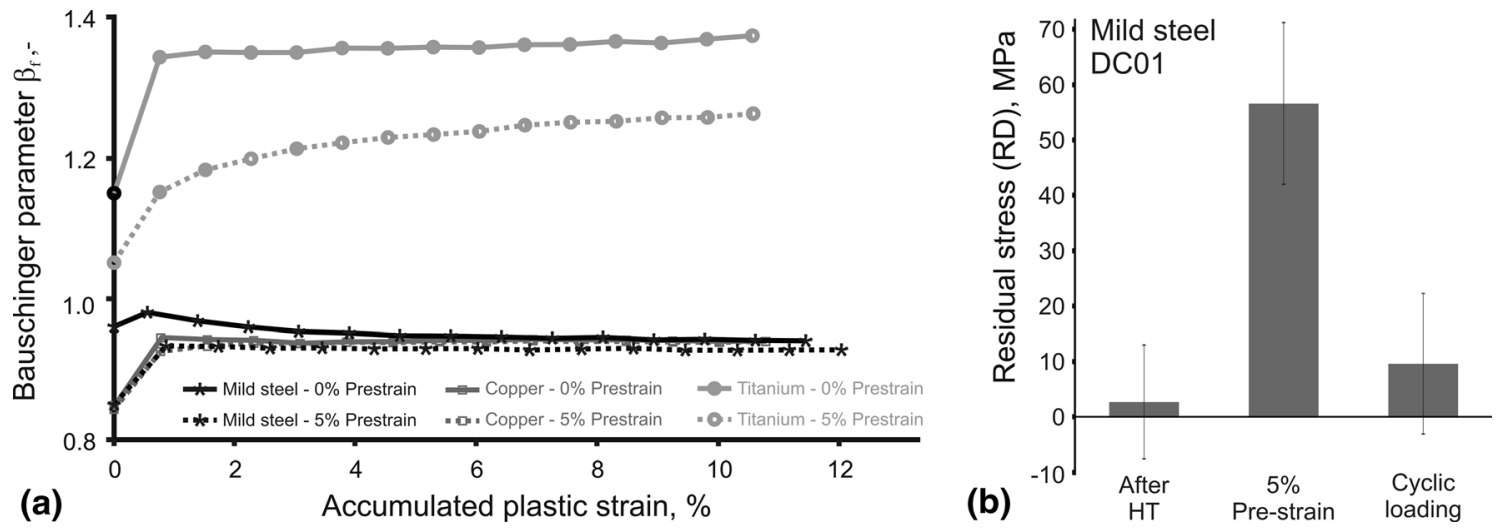

Figure 6 Evolution of the Bauschinger parameter for all investigated materials for different pre-strains at a testing amplitude of $\Delta \varepsilon / 2=0.52 \%$ (a) and the residual stresses along the rolling direction (RD) of the mild steel as determined by x-ray diffraction (b)

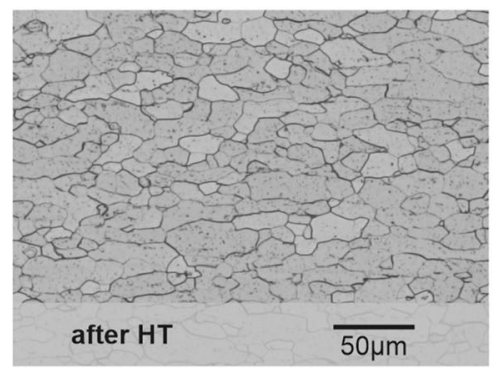

Mild steel

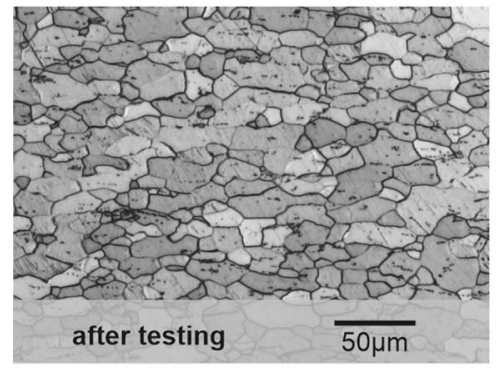

(a)

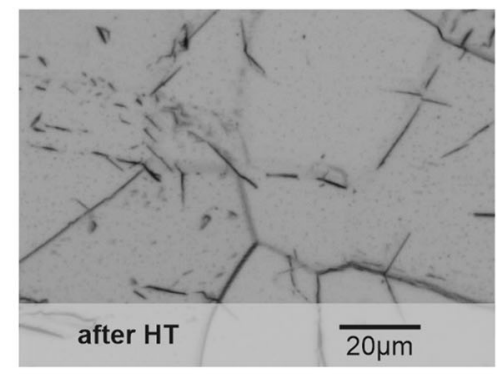

Titanium

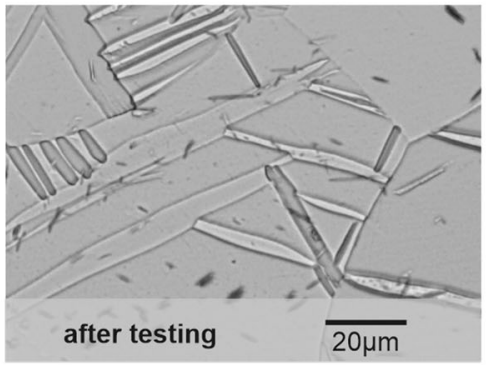

(b)

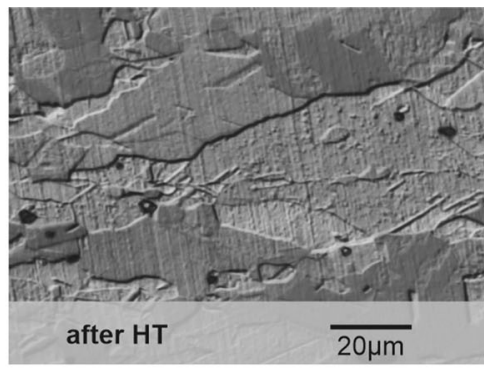

Copper

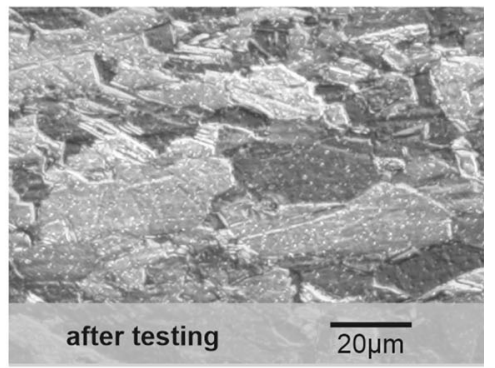

(c)

Figure 7 Micrographs after heat treatment (HT), 5\% pre-strain and after cyclic testing with $\frac{\Delta \varepsilon}{2}=0.52 \%$ of mild steel (a), titanium (b) and copper (c)

to favored formation of deformation twins under compression. This behavior is also expressed in a pronounced decrease in the apparent elastic modulus of up to $61 \mathrm{GPa}$ depending on the stress state (Fig. 8). Under compressive load, almost no evolution is visible, whereas under tensile load substantial reductions in apparent elastic modulus are present depending on the pre-strain and the load amplitude. The less pre-strain is applied and the greater the load amplitude, the more sensitive titanium reacts regarding its apparent elastic properties.

The amplitude-dependent change of the apparent elastic modulus shown in Fig. 8 is a so far hardly investigated phenomenon. Both strain amplitudes used cause an equal amount of material softening, while the apparent elastic behavior is only affected at the larger strain amplitude of $\frac{\Delta \varepsilon}{2}=0.52 \%$. This indicates for the change of the apparent elastic behavior near the elastic-plastic transition, a combined influence of work hardening, microstructural changes and residual stresses. This is in line with the statement in (Ref 2) that the observed phenomena require a complete materialphysical representation and that no simple dependencies can be derived. Yet, one can conclude that:

1. If the material under consideration shows no or only small changes in the yield stress upon cyclic loading, the change of the apparent elastic properties is small as well.

2. The lowering of the apparent elastic modulus during alternating loading is positively correlated with the strain amplitude used and the pre-strain applied.

The technically determined relative springback behavior normalized to the target angle of $90^{\circ}$ is depicted in Fig. 9. For the materials investigated, the largest effect on the technical springback can be linked to the preceding skin passing and the associated thickness reduction that correlates inversely to the springback (Ref 18). 


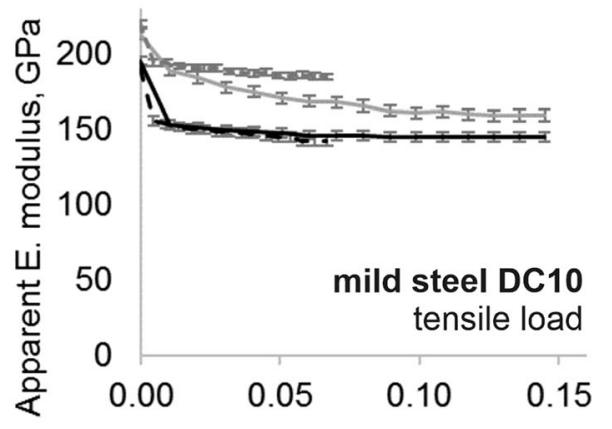

(a) Accumulated plastic strain, -
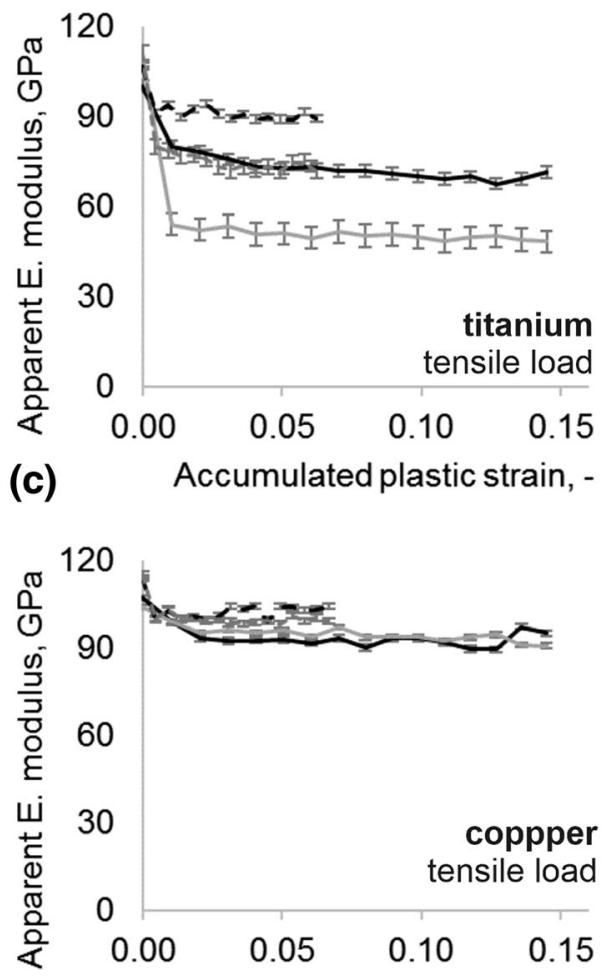

(e) Accumulated plastic strain, -
$-5 \%$ pre-strain - Max. Amplitude
$--5 \%$ pre-strain - Min. Amplitude

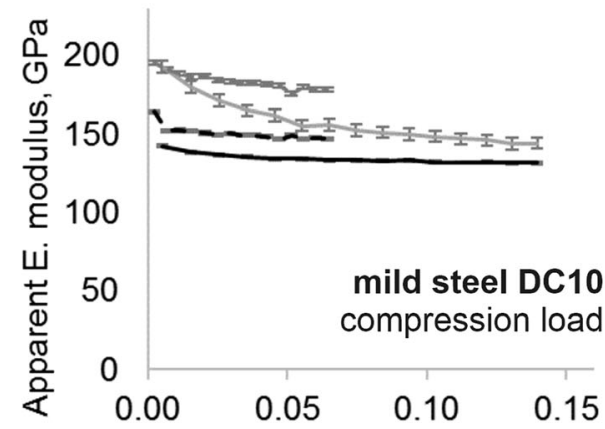

(b) Accumulated plasticstrain, -
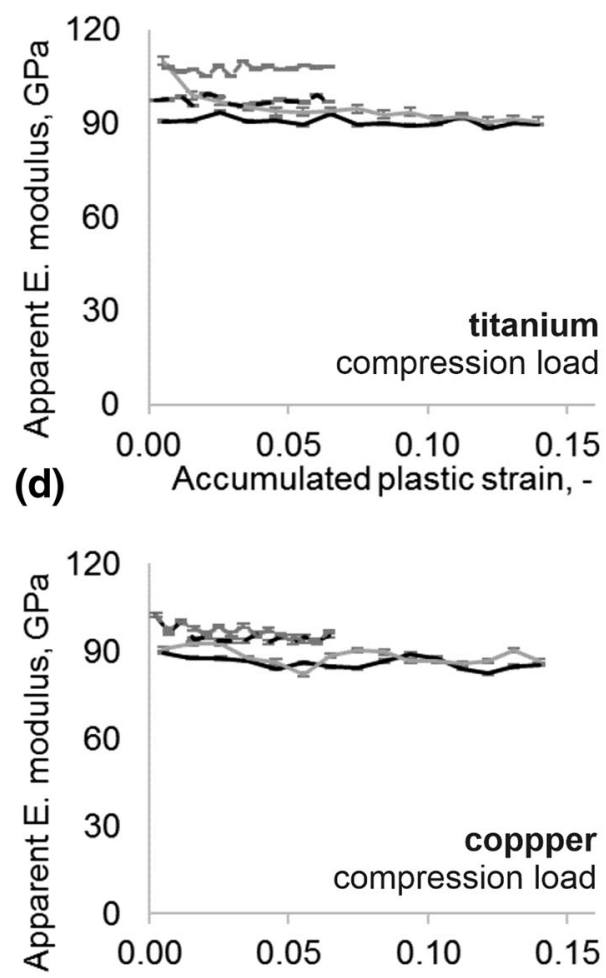

(f)

Figure 8 Pre-strain-dependent evolution of the apparent elastic modulus due to accumulated plastic strain during cyclic testing under tensile and compressive load of mild steel $(\mathrm{a}, \mathrm{b})$, titanium $(\mathrm{c}, \mathrm{d})$ and copper $(\mathrm{e}, \mathrm{f})$

Nevertheless, for the mild steel DC01, the elastic recovery of around $3 \%$ under no pre-strain conditions is reduced to virtually no apparent springback after skin passing indicating a dominant influence of changed material strength. Differences due to cyclic loading are observed especially in samples without pre-strain. Compared to the small amplitude a reduced springback is caused by the higher strain amplitude. Many factors influence the technical springback including material strength, sheet thickness, apparent elastic modulus and residual stresses (Ref 1). Beside the geometric parameters (e.g., thickness and bending angle) the hardening behavior seems to be the decisive factor of the transient material properties with regard to the technical springback. This is revealed by the tests with DC01 (Fig. 9(a)). Despite a reduction of the apparent elastic modulus (Fig. 8a and b), the springback is reduced with increasing accumulated deformation and the associated material softening. This general correlation also exists for the other materials. A decisive influence of the residual stress state was not apparent, because in the specimens considered, the residual stresses were reduced to very small values upon cyclic testing.

As demonstrated in previous works, no implicit dependence on the crystal lattice could be detected (Ref 9). Nevertheless, the material-specific tendency to change its microstructural features influences the general hardening behavior and the elastic properties as a second-order effect.

The present study demonstrates that despite the very small amount of deformation a remarkable variation in the Bauschinger parameters is present and changes in the apparent elastic modulus occur that correlate with (1) the loading amplitude and (2) the amount of pre-strain applied. Transferred to low-cycle 
Mild Steel - DC01

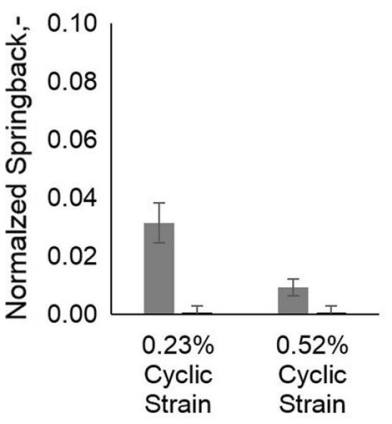

No pre-strain $=5 \%$ pre-strain

(a)
a-Titanium

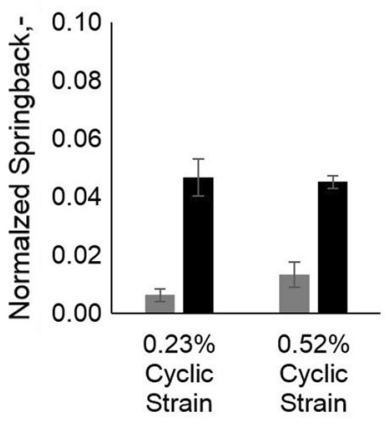

(b)
Copper

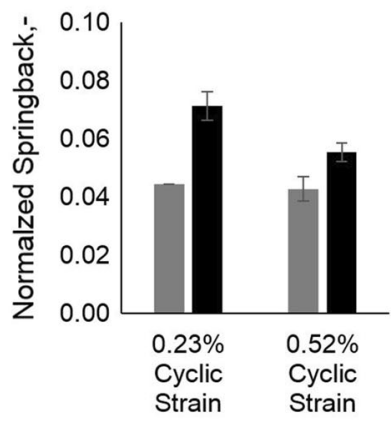

No pre-strain $=5 \%$ pre-strain

(c)

Figure 9 Normalized technical springback as a function of the pre-strain and the strain amplitude for mild steel (a), $\alpha$-titanium (b) and copper (c)

processes with very small degrees of deformation, such as roller leveling, a change in apparent elastic stiffness can be expected based on the presented findings. Since even very small degrees of deformation can lead to a changed stiffness, attention must be paid especially in the field of process modeling. Considering the increasingly important cross process modeling of material properties and parameters, the observed changes in stiffness can lead to variations especially in downstream processing steps and should be considered for further investigations. The data obtained in the current study could be used to validate finite element analysis of springback prediction, and work is underway to better correlate springback with microstructural evolution.

\section{Conclusions}

Alternating low-cycle uniaxial loading with strain amplitudes near the elastic-plastic transition was applied to the three materials DC01, $\alpha$-titanium and CU-DHP. In particular, the influences of pre-strain and the applied strain amplitude were investigated regarding material hardening and changes in the apparent elastic properties. The main findings can be summarized as follows:

- A pre-strain has an effect on the Bauschinger effect and its evolution during subsequent cyclic loading.

- The pronounced Lüders strain of the mild steel DC01 can be eliminated by very small strain amplitudes that slightly exceed the elasto-plastic transition within just one loading cycle.

- Different than mild steel and copper, the hcp $\alpha$-titanium forms twins under compressive stress. These subsequently stabilize the critical compressive stress necessary for further forming. Simultaneous softening in the tensile regime results in a large change of the Bauschinger effect during cyclic testing.

- Fifteen alternating cycles at a strain amplitude of $0.52 \%$ are sufficient to erase the residual stresses in the mild steel introduced at the sheet surface by a preceding skin passing.

- The elastic moduli decreased with increasing accumulated plastic strain for all materials investigated. This effect de- pends on the pre-strain, the load path and occurring microstructural changes.

- In addition to the geometric sample parameters, the materials' hardening behavior is the decisive non-geometric parameter that governs the technical springback after cyclic loading.

\section{Acknowledgments}

Financial support of this study by Deutsche Forschungsgemeinschaft (Grant 290141559) is gratefully acknowledged.

\section{Funding}

Open Access funding enabled and organized by Projekt DEAL.

\section{Open Access}

This article is licensed under a Creative Commons Attribution 4.0 International License, which permits use, sharing, adaptation, distribution and reproduction in any medium or format, as long as you give appropriate credit to the original author(s) and the source, provide a link to the Creative Commons licence, and indicate if changes were made. The images or other third party material in this article are included in the article's Creative Commons licence, unless indicated otherwise in a credit line to the material. If material is not included in the article's Creative Commons licence and your intended use is not permitted by statutory regulation or exceeds the permitted use, you will need to obtain permission directly from the copyright holder. To view a copy of this licence, visit http://creativecommons.org/licenses/by/4.0/.

\section{References}

1. R.K. Lal, V.K. Choubey, J.P. Dwivedi and S. Kumar, Study of Factors Affecting Springback in Sheet Metal Forming and Deep Drawing Process, Mater. Today Proc., 2018, 5, p 4353-4358

2. S. Münstermann, Y. Sparrer, Y. Yao, J. Lian, R. Meya, T. Clausmeyer and A.E. Tekkaya, Effect of Plastic Strain and Ductile Damage on Elastic Modulus of Multiphase Steel and Its Impact on Springback Prediction, AIP Conf. Proc., 2019 https://doi.org/10.1063/1.5112739 
3. A. Abvabi, J. Mendiguren, A. Kupke, B. Rolfe and M. Weiss, Evolution of Elastic Modulus in Roll Forming, Int. J. Mater. Form., 2017, 10(3), p 463-471

4. T. Evertz, H.-M. Sonne, G. Steinbeck and B. Engl, Werkstoffverhalten Unter Zügiger Elastischer Beanspruchung, Materwiss. Werksttech., 2004, 35(8), p 514-521. https://doi.org/10.1002/mawe.200400768

5. S.B. Chikalthankar, G.D. Belurkar and V.M. Nandedkar, Factors Affecting on Springback in Sheet Metal Bending: A Review, Int. J. Eng. Adv. Technol., 2014, 3(4), p 247-251

6. J. Marnette, B. Rolfe, P. Hodgson and M. Weiss, Numerical Investigation on the Effect of Skin Passing and Roller Leveling on the Bending Behaviour of Mild Steel, AIP Conf. Proc., 2014 https://d oi.org/10.1063/1.4850011

7. C. Zener, Elasticity and Anelasticity of Metals, University of Chicago Press, Chicago, 1948

8. J. Marnette, B. Rolfe, P. Hodgson and M. Weiss, Effect of Roller Leveling on the Bending Behaviour of Aged Steel Strip, Steel Res. Int., 2012, SPL. ISSUE, p 699-702

9. K. Barienti, D. Wolff, S. Herbst, F. Nürnberger and H.J. Maier, Influence of Alternating Short-Cycle Bending on the Mechanical Properties of Copper, $\alpha$-Titanium and the Mild Steel DC01, J. Mater Eng. Perform., 2019, 28, p 7165-7170

10. E. Demler, D. Rodman, M. Rodman, G. Gerstein, O. Grydin, A.A Briukhanov, C. Klose, F. Nürnberger and H.J. Maier, The Influence of Alternating Low-Cycle Bending Loads on Sheet Properties Having an Hcp Crystal Lattice, J. Mater. Eng. Perform., 2018, 27, p 541-549

11. J. Kim, K.C. Park and D.N. Kim, Investigating the Fluting Defect in VBending Due to the Yield-Point Phenomenon and Its Reduction via Roller-Leveling Process, J. Mater. Process. Technol., 2019, 270, p 5981
12. A. Zerovnik, R. Kunc and I. Prebil, Yield-Point Phenomenon in Constitutive Models of Cyclic Plasticity, Comput. Mater. Sci., 2010, 49(3), p 473-482

13. E. Silvestre, J. Mendiguren, L. Galdos and E. Sáenz De Argandoña, Comparison of the Hardening Behaviour of Different Steel Families: From Mild and Stainless Steel to Advanced High Strength Steels, Int. J. Mech. Sci., 2015, 101-102, p 10-20. https://doi.org/10.1016/j.ijmec sci.2015.07.013

14. A. Abvabi, B. Rolfe, P.D. Hodgson and M. Weiss, The Influence of Residual Stress on a Roll Forming Process, Int. J. Mech. Sci., 2015, 101-102, p 124-136

15. S. Münstermann, Y. Feng and W. Bleck, Influencing Parameters on Elastic Modulus of Steels, Can. Metall. Q., 2014, 53(3), p 264-273. h ttps://doi.org/10.1179/1879139514Y.0000000127

16. J.-Y. Lee, M.-G. Lee, F. Barlat, K.-H. Chung and D.-J. Kim, Effect of Nonlinear Multi-axial ELASTICITY And anisotropic Plasticity on Quasi-static Dent Properties of Automotive Steel Sheets, Int. J. Solids Struct., 2016, 87, p 254-266. https://doi.org/10.1016/j.ijsolstr.2016.01. 020

17. E. Orowan, Causes and Effect of Internal Stresses, in Proceedings of the Symposium on Internal Stress and Fatigue of Metals, 1959, p. 5980

18. B.M. Hance, Springback as a Function of Strength and Thickness Variability in High Strength Sheet Steels, SAE Trans., 2000, 109, p 861-869

Publisher's Note Springer Nature remains neutral with regard to jurisdictional claims in published maps and institutional affiliations. 